\title{
Bronchoscopic Intervention May be Associated with Better Outcomes in Mechanically Ventilated Coronavirus Disease-19 Patients: A Case Series
}

\author{
Dewiyana A. Kusmana ${ }^{1 *}$, Edwin Adhi Darmawan Batubara ${ }^{2}$, Raka Aldy Nugraha ${ }^{3}$, Theresia Rasta Karina ${ }^{4}$, \\ Natasha Setyasty Primaditta ${ }^{4}$ \\ ${ }^{1}$ Department of Pulmonology, Pulmonologist, Gatot Soebroto Army Hospital, Jakarta, Indonesia; ${ }^{2}$ Department of General \\ Practice, Mintohardjo Navy Hospital, Jakarta, Indonesia; ${ }^{3}$ Department of General Practice, Depok University of Indonesia \\ Hospital, Jakarta, Indonesia; ${ }^{4}$ Department of General Practice, Gatot Soebroto Army Hospital, Jakarta, Indonesia
}

Edited by: Mirko Spiroski Citation: Kusmana DA, Batubara EAD, Nugraha RA, Karina TR, Primaditta NS. Bronchoscopic Intervention May be Associated with Better Outcomes in Mechanically Ventilated Coronavirus Disease-19 Patients: A Case Series,
Open Access Maced J Med Sci. 2020 Oct 14; 8(T1):276-281 https://doi.org/10.3889/oamjms.2020.5390 Keywords: Coronavirus disease-19 Acute respiratory distress syndrome; Bronchoscopy intervention *Correspondence: Dewiaya A. Kusmana, Department Pulmonology, Gatot Soebroto Army Hospila, Jakarta 10410, Indonesia. E-mail: dewiyana.ku@gmail.com Revised: $20-$ Sep-2020
Accepted: $04-$ Oct-2020 Copyright: $\odot 2020$ Dewiyana A. Kusmana, Edwin Adhi Darmawan Batubara, Raka Aldy Nugraha, Theresia Rasta Karina, Natasha Setyasty Primaditta Funding: Publication of this article was financially
pported by the Scientific Foundation SPIROSKI, Skopje, Republic of Macedoni Competing Interests: The authors have declared that no
competing interests exist. under the terms of the Creative Commons AttributionNonCommercial 4.0 International License (CC BY-NC 4.0)

\begin{abstract}
BACKGROUND: The emergence of a new strain of coronavirus infection, the coronavirus infection disease 2019 (COVID-19), has been a pandemic burden across the globe. Severe COVID-19, particularly in patients with acute respiratory distress syndrome (ARDS), is associated with increased risk of admission to intensive care unit (ICU), mechanical ventilation, and mortality. Bronchoscopy has been widely employed as an adjunctive therapy in mechanically ventilated patients. However, the use of bronchoscopy in patients with COVID-19 has been strictly limited due to aerosol transmission.

CASE REPORT: We reported 3 COVID-19 Cases presented to the hospital with ARDS. All of the patients were immediately intubated to improve oxygenation. During admission, the patients produced immense airway secretions that might have resulted in partial airway obstruction. A conventional tracheal suctioning did not help to promote clinical improvement. We decided to perform bronchoscopy with controlled suctioning by following a very tight protocol to prevent aerosol formation. A significant clinical and respiratory improvement was observed in all patients following bronchoscopy. Three of them were transferred to regular ward, however, one patient died during hospitalization.

CONCLUSION: Bronchoscopic procedures may provide significant therapeutic benefits in severe COVID-19 patients. However, it should be kept in mind that this procedure should only be performed with a rigorous protocol to
\end{abstract} reduce the risk of aerosol generation and subsequent viral transmission.

\section{Introduction}

The emergence of a new strain of coronavirus has been a pandemic burden across the globe. Due to the similarity in the genomic sequence and clinical consequence with the previous strains of coronavirus, it has later been named as severe acute respiratory syndrome coronavirus-2 (SARS-CoV-2) that causes a disease called coronavirus infection disease 2019 (COVID-19) [1], [2]. Firstly reported in Wuhan, Hubei Province, China, by the end of December 2019, the number of confirmed SARS-CoV-2 infection cases has been dramatically increasing [3]. As per July 1 , 2020, there have been more than 10.6 million cases and over 514,000 COVID-19-related deaths reported by the World Health Organization. A substantial number of new cases has been published in the United States recently, making it the only country that reaches a total of more than 1 million confirmed cases.
On the other hand, although it has been reported to be steadily increasing, the incidence rates in Indonesia are not as overwhelmingly high, as stated in the different parts of the world. This may be attributed to the low rates of screening in our population. However, the case fatality rate of SARS-CoV-2 infection in Indonesia is relatively higher, indicated by the mortality rates of $7.2 \%$ [4]. Severe COVID-19, particularly in patients with acute respiratory distress syndrome (ARDS), is associated with an increased risk of admission to the intensive care unit (ICU), mechanical ventilation, and mortality [5], [6]. It has been well documented that patients suffering from ARDS most probably produce thick mucus secretion. This is associated with an increased risk of mucous plug formation and subsequent lung collapse [7]. Similar characteristics of airway secretion have also been reported in COVID-19 infection [8]. Proper and timely secretion management plays essential roles in both the prevention and treatment of respiratory failure. Bronchoscopy has been widely employed for various purposes in severe 
pulmonary infection, particularly among mechanically ventilated patients. This includes therapeutic suctioning as a part of effective secretion management, both as diagnostic and therapeutic measures [7], [9], [10]. However, the use of bronchoscopy in patients with COVID-19 has been strictly limited as it is associated with the aerosol generation and intensifies viral transmission. It can be performed only in certain situations, such as mucous plug removal as well as to ascertain the presence of any coinfection in patients who do not respond to the standard therapy, by following a very tight protocol as proposed by currently available consensus [3], [11], [12], [13], [14]. However, to the best of our knowledge, there is no presently available data regarding the use of the bronchoscopic intervention in COVID-19 patients with severe clinical presentation. Here, we describe the outcomes of bronchoscopic intervention performed in three cases of mechanically ventilated, COVID-19-confirmed patients.

\section{Case I}

A 47-year-old woman was admitted to our facility due to shortness of breath accompanied cough since 1 day before admission. The patient also reported a 1-week course of fever, nausea, and vomitus. She had neither a history of lung nor heart disease. The patient was diagnosed with severe pneumonia. On the $3^{\text {rd }}$ day of hospitalization, the patient experienced clinical deterioration with more intense dyspnea. The initial clinical examination showed decreased oxygen saturation $\left(\mathrm{SpO}_{2}\right)$ to $84 \%$, and the patient was immediately given oxygen supplementation. Arterial blood gas (ABG) analysis showed pH 7.480, $\mathrm{PaCO}_{2}$ $34.6 \mathrm{mmHg}, \mathrm{PaO}_{2} 159.5 \mathrm{mmHg}$, and $\mathrm{SpO}_{2} 98 \%$. Chest $\mathrm{X}$-ray results were suggestive for bilateral pneumonia (Table 1). The patient was decided to undergo early intubation with subsequent mechanical ventilation. The following ventilator setting was used: Volume-controlled synchronized intermittent mandatory ventilation (VC-SIMV) mode, a fraction of inspired oxygen $\left(\mathrm{FiO}_{2}\right)$ $70 \%$, positive end-expiratory pressure (PEEP) 12 $\mathrm{cmH}_{2} \mathrm{O}$, pressure support $12 \mathrm{cmH}_{2} \mathrm{O}$, tidal volume (VT) $300 \mathrm{ml}$, and respiratory rate (RR) 20 breaths/ min that resulted in oxygen saturation $\left(\mathrm{SpO}_{2}\right)$ of $98 \%$ immediately. One day following intubation, the patient showed clinical improvement. Subsequent blood gas analysis results showed improved $\mathrm{PaO}_{2}$ that reached $195.5 \mathrm{mmHg}$. On the next day, from the physical examination, it was found that there was an excessive mucus production that might have partially obstructed the patient's airway. We performed tracheal suctioning as the primary measure to evacuate the obstructing mucus; however, no clinical improvement was observed. Subsequently, we decided to perform controlled suction through bronchoscopy. Pre-bronchoscopy ABG showed $\mathrm{pH}$ 7.492, $\mathrm{PaO}_{2} 150 \mathrm{mmHg}, \mathrm{PaCO}_{2} 34 \mathrm{mmHg}$, and $\mathrm{SpO}_{2} 99 \%$. Even when there was no vivid hypoxemia, we considered that early bronchoscopic suction would be a favorable measure to improve the patient's clinical status. The ventilator parameters before bronchoscopy were set as pressure support ventilation (PSV), PEEP +5 $\mathrm{cmH}_{2} \mathrm{O}$, RR 19 breaths/min, VT $400 \mathrm{ml}$, FiO, 40\%, and $\mathrm{PS} 6 \mathrm{cmH}_{2} \mathrm{O}$. Bronchoscopy was performed on day 24 of hospitalization in a negative-pressured room. We use fentanyl, atracurium, and midazolam as sedation before bronchoscopy. Bronchoscopy was performed with Olympus TF180, and we found a large amount of thick reddish black-colored secretions were evacuated from the lower airway. Ventilator settings were adjusted to SIMV, PEEP +6 cmH2O, RR 15 breaths/mnt, VT $360 \mathrm{ml}, \mathrm{FiO}_{2} 70 \%$, and PS $5 \mathrm{cmH}_{2} \mathrm{O}$. Immediate postbronchoscopy $\mathrm{ABG}$ evaluations showed the following results: $\mathrm{pH} 7.5230, \mathrm{pO}_{2} 242.9 \mathrm{mmHg}, \mathrm{pCO}_{2} 29 \mathrm{mmHg}$ (Figure 1). On the following days, the patient showed significant clinical and respiratory improvement. Weaning of the respiratory support was started on day 3 and was discharged from the ICU on 28 days of hospitalization.

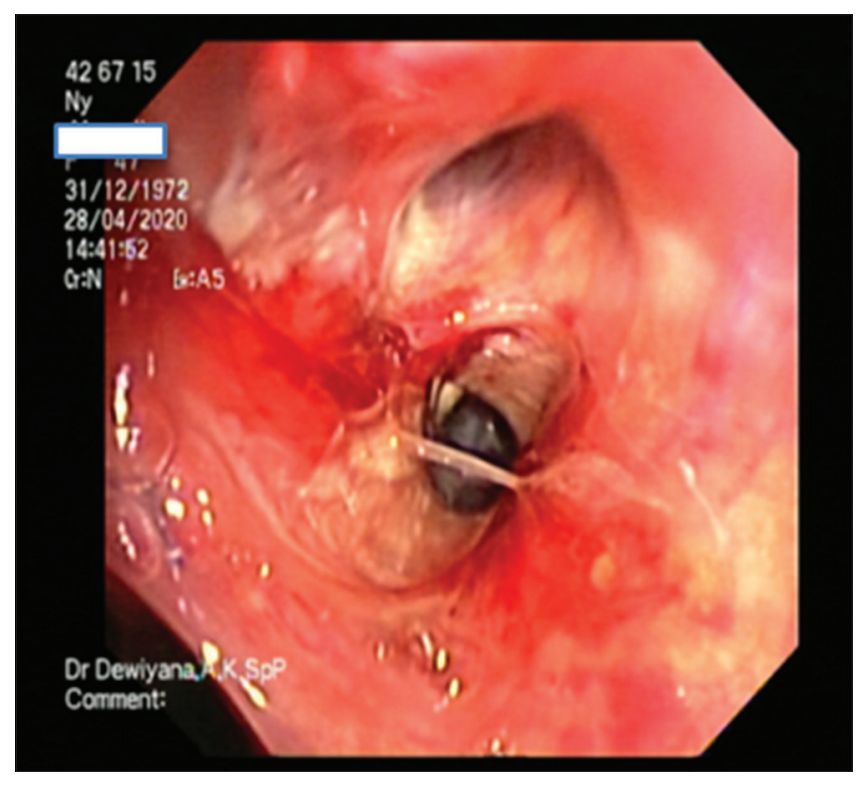

Figure 1: Bronchsocopy showed thick reddish black colored secretions

\section{Case II}

A 70-year-old man was admitted to our facility due to cough and fatigue. After a series of examination, the patient was confirmed to have suffered from COVID-19 pneumonia. On day 16 post-hospital admission, the patient experienced worsening shortness of breath. Immediate ABG evaluation showed $\mathrm{pH} 7.48$, $\mathrm{PCO}_{2} 31.5 \mathrm{mmHg}, \mathrm{PO}_{2} 121.3 \mathrm{mmHg}$, and $\mathrm{SpO}_{2} 84.3 \%$. Accordingly, he was decided to undergo endotracheal intubation with subsequent mechanical ventilation support with the following ventilator settings: VC-SiMV, VT $400 \mathrm{ml}$, PEEP 10, PSV 10, RR 12 breaths/minute, and $\mathrm{FiO}_{2} 80 \%$. A significant hemodynamic improvement was observed following mechanical ventilation. Around 6 days following intubation, it was noted that the patient produced enormous airway secretions, as evidenced 
by pulmonary auscultation showing significant pulmonary rales. Further, ABG showed pH 7.57, $\mathrm{PCO}_{2} 26.6 \mathrm{mmHg}$, and $\mathrm{PO}_{2} 145.3 \mathrm{mmHg}$. Similarly, tracheal suction was performed initially as an effort to evacuate the obstructing mucus. However, the attempt was not successful. Therefore, a controlled suction was also performed through bronchoscopy. We were able to evacuate the thick obstructing secretion from the lower respiratory tract. The bronchoscopy showed the presence of thick secretion obstructing the distal trachea, which was removed (Figure 2). Subsequently, the ventilatory settings were adjusted to SIMV, PEEP $+6 \mathrm{cmH}_{2} \mathrm{O}, \mathrm{RR} 12$ breaths/mnt, VT $360 \mathrm{ml}, \mathrm{FiO}_{2} 60 \%$, and $\mathrm{PS} 6 \mathrm{cmH}_{2} \mathrm{O}$ after the procedure. The patient demonstrated clinical improvement. Subsequent ABG evaluation showed $\mathrm{pH} 7.52, \mathrm{PCO}_{2} 35.1 \mathrm{mmHg}$, and $\mathrm{PO}_{2} 171.7 \mathrm{mmHg}$. Ventilator weaning was successfully attempted on day 16 , and the patient was discharged from the ICU on 26 days of hospitalization.

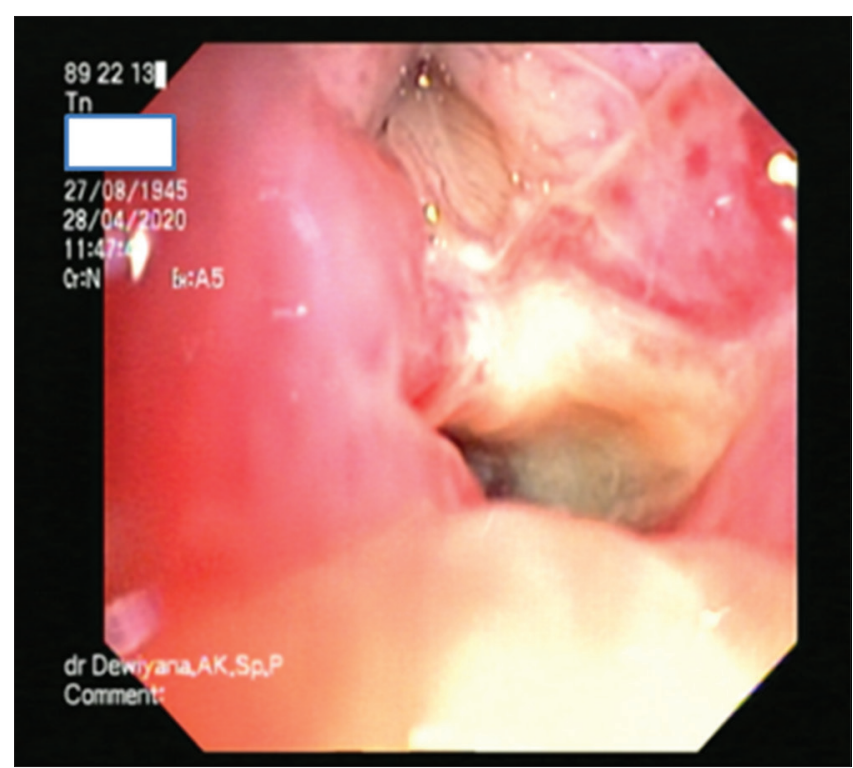

Figure 2: Bronchoscopy showed thick secretion obstrutcting the ditstal trachea

\section{Case III}

A 75-year-old man was confirmed to have suffered from COVID-19 pneumonia. The patient had a history of diabetes mellitus, hypertension, and cardiac disease. On day 3 post-hospital admission, the patient experienced worsening shortness of breath and decreasing of saturation. Immediate $A B G$ evaluation showed $\mathrm{pH} 7.5, \mathrm{PCO}_{2} 22.6 \mathrm{mmHg}, \mathrm{PO}_{2} 60.3 \mathrm{mmHg}$, and $\mathrm{SpO}_{2} 86 \%$. Accordingly, he was decided to undergo endotracheal intubation with subsequent mechanical ventilation support with the following ventilator settings: VC-SiMV, VT 600 ml, PEEP 10, PSV 10, RR 12 breaths/min, and $\mathrm{FiO}_{2}$ 60\%. A significant hemodynamic improvement was observed following mechanical ventilation. Around 7 days following intubation, tracheal suction was performed initially as an effort to evacuate thick and green mucoid obstructing mucus. However, the attempt was not successful. Therefore, a controlled suction was also performed through bronchoscopy. The bronchoscopy showed thick yellow mucoid secretion, hyperemic in entire bronchus lumen, and prone to bleed (Figure 3). There are no adjusting ventilatory settings. The patient demonstrated clinical improvement. Subsequent ABG evaluation showed $\mathrm{pH}$ 7.466, $\mathrm{PCO}_{2}$ $34.8 \mathrm{mmHg}$, and $\mathrm{PO}_{2} 173.2 \mathrm{mmHg}$. Ventilator weaning was successfully attempted on day three, and the patient was discharged from the ICU on 15 days of hospitalization. Unfortunately, the patient had a cardiac arrest and died in the hospital ward.

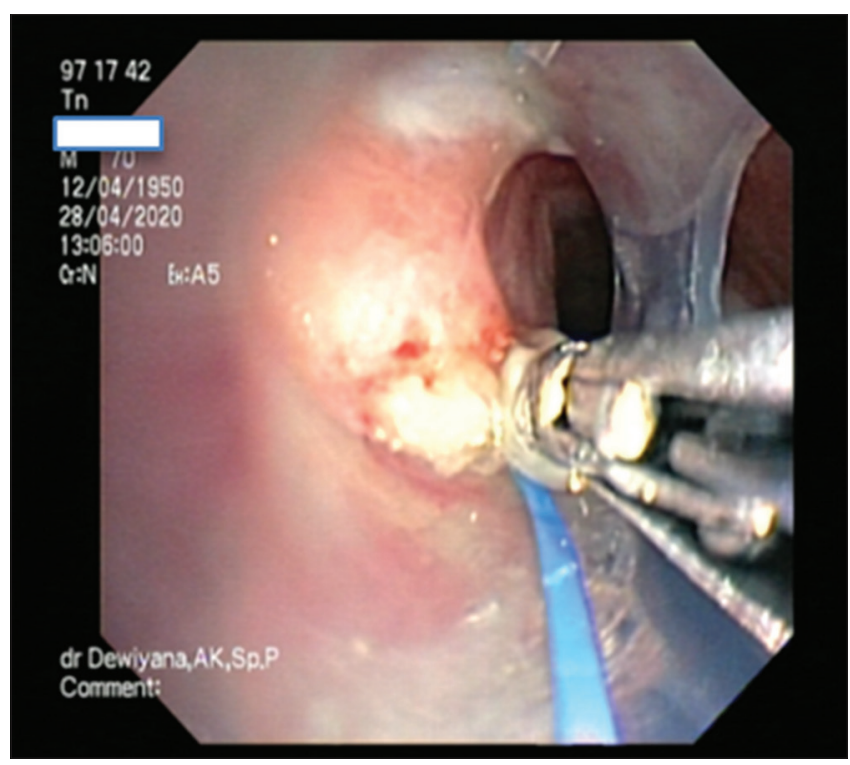

Figure 3: Bronchoscopy showed thick yellow mucoid secretion and hyperemic bronchus lumen

\section{Discussion}

COVID-19 is an extremely infectious disease caused by a newly identified SARS-CoV-2 virus. It has affected more than 3.5 million individuals in almost every country within the past 4 months [4]. SARS-CoV-2 is an enveloped, non-segmented, positive-sense, and single-stranded RNA virus that is considered a member of beta-coronavirus [15], [16]. The clinical presentations of COVID-19 vary among individuals. Some people may not have any signs and symptoms of infection and become carriers. Some others may develop symptoms within 14 days following the initial exposure to the viral particles [17], [18]. The majority of patients (81\%) demonstrated mild symptoms; only $14 \%$ and $5 \%$ of patients presented with a severe and critical disease, respectively [19]. The most common symptoms reported include fever (83-98\%), cough (50-80\%), fatigue (34-69\%), and dyspnea (20-40\%) [5], [20], [21], [22]. Patients with severe manifestations may present with signs and symptoms of pneumonia, ARDS, sepsis, and septic shock [23]. Patients who initially present with mild 
Table 1: Characteristics of the presented patients

\begin{tabular}{|c|c|c|c|}
\hline Parameters & Patient 1 & Patient 2 & Patient 3 \\
\hline Age (years) & 47 & 70 & 74 \\
\hline Sex & Female & Male & Male \\
\hline \multicolumn{4}{|l|}{ Symptoms } \\
\hline Fever & Yes & No & Yes \\
\hline Cough & Yes & Yes & Yes \\
\hline Myalgia or fatigue & Yes & Yes & Yes \\
\hline Headache & No & No & No \\
\hline Hemoptysis & No & No & No \\
\hline Diarrhea & No & No & No \\
\hline Dyspnea & Yes & No & Yes \\
\hline \multicolumn{4}{|l|}{ Comorbidities } \\
\hline Diabetes & No & No & Yes \\
\hline Hypertension & No & No & Yes \\
\hline Cardiovascular disease & No & No & Yes \\
\hline Chronic obstructive pulmonary disease & No & No & No \\
\hline Malignancy & No & No & No \\
\hline Chronic liver disease & No & No & No \\
\hline Immunosuppresion & No & No & No \\
\hline \multicolumn{4}{|l|}{ Vital signs at admission } \\
\hline Blood pressure $(\mathrm{mmHg})$ & $136 / 80$ & $124 / 73$ & $167 / 81$ \\
\hline Heart rate $(\mathrm{bpm})$ & 103 & 68 & 98 \\
\hline $\operatorname{RR}(\times / \min )$ & 30 & 20 & 28 \\
\hline Temperature $\left({ }^{\circ} \mathrm{C}\right)$ & 38 & 36 & 36.8 \\
\hline Oxygen saturation (\%) & $84 \%$ & $88 \%$ & $98 \%$ \\
\hline \multicolumn{4}{|l|}{ Laboratory parameters* } \\
\hline Hemoglobin $(\mathrm{g} / \mathrm{dL})$ & 11.3 & 11.2 & 16.4 \\
\hline White blood cell count $(\times 10)$ & 5820 & 7490 & 14690 \\
\hline Neutrophil count $(\times 10)$ & 80 & 56 & 91 \\
\hline Lymphocyte count $(\times 10)$ & 14 & 37 & 6 \\
\hline Platelet count $(\times 10)$ & 231 & 227 & 296 \\
\hline $\mathrm{PT}(\mathrm{s})$ & 13.1 & 11.8 & 10.9 \\
\hline APTT (s) & 37.4 & 40 & 25.9 \\
\hline $\mathrm{D}$-dimer (mg/dL) & 380 & 3480 & 2130 \\
\hline Albumin $(\mathrm{g} / \mathrm{L})$ & 3.9 & 3.2 & 2.9 \\
\hline $\operatorname{ALT}(\mathrm{U} / \mathrm{L})$ & 39 & 19 & 40 \\
\hline AST (U/L) & 52 & 21 & 25 \\
\hline Sodium & 145 & 130 & 137 \\
\hline Potassium & 3.6 & 4.1 & 3.9 \\
\hline Creatinine (mg/dl) & 0.79 & 1.01 & 2.27 \\
\hline Ureum (mg/dl) & 19 & 42 & 70 \\
\hline Swab results & Yes & Yes & Yes \\
\hline CRP & 7.84 & 14.14 & 24.47 \\
\hline Radiographic signs of pneumonia & Yes & Yes & Yes \\
\hline \multicolumn{4}{|l|}{ Treatment } \\
\hline Antiviral & Yes & Yes & Yes \\
\hline Antifungal & No & No & No \\
\hline Antibiotic & Yes & Yes & Yes \\
\hline Antiparasitic & Yes & Yes & Yes \\
\hline High-dose Vitamin C & Yes & Yes & Yes \\
\hline \multicolumn{4}{|l|}{ Ventilator-related parameters } \\
\hline Onset to mechanical ventilation (days) & 3 & 16 & 2 \\
\hline Modea & VC-SIMV & VC-SiMV & VC-SiMV \\
\hline Peak pressure $\left(\mathrm{cmH}_{2} \mathrm{O}\right) \mathrm{a}$ & 12 & 10 & 10 \\
\hline $\operatorname{PEEP}\left(\mathrm{cmH}_{2} \mathrm{O}\right) \mathrm{a}$ & 12 & 10 & 10 \\
\hline \multirow{2}{*}{\multicolumn{4}{|c|}{ Bronchoscopy-related parameters }} \\
\hline & & & \\
\hline Day of bronchoscopy & 24 & 28 & 10 \\
\hline Onset to bronchoscopy (days) & 31 & 31 & 13 \\
\hline Positioning & Prone & Prone & Prone \\
\hline Bronchoscope diameter $(\mathrm{mm})$ & 2.1 & 2.1 & 2.1 \\
\hline ETT diameter $(\mathrm{mm})$ & 7.5 & 7.5 & 7.5 \\
\hline BAL & No & No & No \\
\hline \multicolumn{4}{|l|}{ Monitoring } \\
\hline \multicolumn{4}{|l|}{$\mathrm{MAP}(\mathrm{mmHg})$} \\
\hline Baseline & 83 & 86 & 93 \\
\hline During bronchoscopy & 93 & 86 & 93 \\
\hline \multicolumn{4}{|l|}{ Oxygen saturation (\%) } \\
\hline Baseline & 99 & 99 & 99 \\
\hline During bronchoscopy & 99 & 99 & 98 \\
\hline Outcomes & & & \\
\hline Discharged from hospital & Yes & Yes & No \\
\hline Discharged from ICU & Yes & Yes & Yes \\
\hline Dead & No & No & Yes \\
\hline
\end{tabular}

ALT: Alanine aminotransferase, APTT: Activated partial thromboplastin time, AST: Aspartate aminotransferase, BAL: Bronchoalveolar lavage, CRP: C-reactive protein; $\mathrm{PCO}_{2}$ : Carbon dioxide, ETT: Endotracheal tube, $\mathrm{FiO}_{2}$ : Fractional concentration of inspired oxygen, ICU: Intensive care unit, LDH: Lactate dehydrogenase, LOS: Length of stay, MAP: Mean arterial pressure, PCT: Procalcitonin, PEEP: Positive end-expiratory pressure, PT: Prothrombin time, VC-SIMV: Volume-controlled synchronized intermittent mandatory ventilation, RR: Respiratory rate.

symptoms could also experience clinical progression toward more severe illness. Rapid progression can also be encountered in an otherwise healthy patient without any significant medical history.

Goh et al. reported a case with a similar pattern of progression affecting a 64-year-old Singaporean man. The patient presented to the hospital with mild symptoms since around 1 week before admission and rapidly deteriorated with severe hypoxemic respiratory failure within only $48 \mathrm{~h}$ following admission [24]. Other evidence also suggested that the median time of ARDS development was 2 days from the admission day [6]. All of our cases presented with relatively mild disease complaining of having some respiratory and constitutional symptoms, including fever, cough, fatigue, and dyspnea. Following the previous evidence, the first patient demonstrated rapid progression, of which she demonstrated worsening of her clinical status within 3 days of admission. The second case, on the other hand, demonstrated a relatively slower clinical course, where the patient experienced an intense worsening of his complaints after 2 weeks of hospitalization.

One of the biggest concerns in COVID19 is a further compromise in respiratory function. It has been noted that COVID-19 patients, particularly those who develop ARDS, produce thick mucus secretion. This puts the patients at a substantial risk of developing airway obstruction due to plug formation and subsequent lung collapse [7], [8]. Hence, airway management and optimal oxygenation serve as the constructing pillars in the management of severe COVID-19 infection. The concept of early intubation in COVID-19 patients has been a matter of debate. It is noteworthy that mechanical ventilation itself can exacerbate functional and structural alterations in the lung and is related to the morbidity and mortality in ARDS [25]. Therefore, timely, but not premature, endotracheal intubation is always preferred [26]. In our cases, all of the patients experienced clinical deterioration. Both of the patients experienced respiratory alkalosis, as indicated by their $A B G$ results. Hence, endotracheal intubation was performed, followed by mechanical ventilation which resulted in clinical improvement. During observation in the ICU, both patients showed clinically significant production of airway secretions, as evidenced by abnormal lung sound on physical examination. Conventional tracheal suction has failed to evacuate the airway secretion, and hence, bronchoscopy was scheduled to vacate the secretion and prevent further airway compromise. Conventionally, bronchoscopy has been widely used as a standard procedure in the setting of severe respiratory problems for both diagnostic and therapeutic purposes in patients with a critical illness [10]. Unfortunately, the practice of performing bronchoscopy during the COVID-19 pandemic has been very restricted. Bronchoscopy is considered an aerosol-generating procedure, and hence, it possesses a substantial risk of viral transmission to the surrounding and puts both medical professionals and unconfirmed patients at risk of getting the infection. Therefore, it is always recommended to consider the risks and benefits of performing bronchoscopy, particularly among patients with confirmed COVID-19 disease. The decision should be individualized based on the patient's clinical condition. Once decided to perform a bronchoscopic 
intervention, it has to be done only in a negativepressure room and by a highly experienced clinician to minimize the amount of time needed to complete the response. It is recommended to perform bronchoscopy with general anesthesia as well as with muscle relaxant administration while avoiding emergent intubation to reduce the risk of aerosol generation. Standard personal protective equipment and disinfection protocol are highly warranted [14]. Indications for performing bronchoscopy during COVID-19 pandemic have been categorized into emergent, semi-urgent, and elective indications. Patients with symptomatic central airway obstruction related to either neoplasm, foreign body aspiration, or mucous plug; massive hemoptysis, tracheal stenosis, and stent migration should be referred for further bronchoscopic evaluation. As for the evaluation of lung nodules, mediastinal lymph node enlargement, whole pulmonary lavage, suspected lung infection in patients with impaired immune function, assessment of obliterative bronchiolitis in transplant recipients, as well as evaluation of lobar atelectasis, bronchoscopy is advised to be performed in a semiurgent manner. Among patients in an otherwise stable condition, elective bronchoscopy can be performed for tracheobronchomalacia evaluation, bronchial thermoplastic, cryobiopsy, as well as bronchoscopic lung volume reduction surgery [11], [14].

The role of bronchoscopy in the management of patients with a severe phenotype of COVID-19 infection is minimal. Bronchial or pulmonary toileting is not recommended as a routine therapeutic intervention in these subsets of patients. However, therapeutic aspiration is advisable in patients with airway obstruction due to mucous impaction that impairs gas exchange function. In our cases, the main reasons for performing bronchoscopy were the evidence of enormous airway secretions, as evidenced by clinical examination. We decided to perform bronchoscopy-directed bronchial toilet as an effort to help to evacuate the abundant mucoid secretion in the patients lower respiratory tract and to prevent the formation of mucus plug. We performed this bronchoscopic intervention under a very secure protocol as proposed by various consensus. Following the response, the patients showed favorable clinical and hemodynamic outcomes. Weaning of the mechanical ventilation could be performed earlier with desirable results. One of the primary concerns in performing bronchoscopy is which technique would result in a limitation of infection spread while maintaining the safety of the procedure. Some data suggested that prone positioning is associated with a reduction in mortality in mechanically ventilated patients with severe ARDS and that bronchoscopy performed in a prone position is safe without significantly aggravating the risk of clinical deterioration [9], [27]. In addition, fiberoptic bronchoscopy performed in a prone position helps to avoid undesirable premature interruption of mechanical ventilation and consequent loss of physiological gains, an increase in intrapulmonary shunt, a fall in the oxygen saturation as well as elevated pulmonary artery resistance [9].

At present, there is no standardized recommendation on a ventilator setting during bronchoscopy. Guarracino et al. (2012) successfully and safely performed bronchoscopy by increasing $\mathrm{FiO}_{2}$ to 1 , reducing PEEP level and respiratory frequency to avoid an increase in PEEP while increasing inspiratory pressure to maintain minute volume and prevent an increase in carbon dioxide [9]. Some data suggested that bronchoscopic tube internal diameter of $4 \mathrm{~mm}$ is optimal and safer in patients with ARDS [7]. In a case series of patients with severe ARDS who were mechanically ventilated, Kalchiem-Dekel et al. (2018) showed that no significant hemodynamic compromise was observed during bronchoscopic aspiration and $\mathrm{BAL}$ procedures using a maximum internal diameter of $4 \mathrm{~mm}$ and without changing the mode of mechanical ventilation except for $100 \% \mathrm{FiO}_{2}$. However, significant oxygen desaturation and rising in $\mathrm{COs}_{2}$ pressure were observed in one patient. At last, 4 out of 7 patients survived 30 days following discharge from ICU [28].

\section{Conclusion}

Bronchoscopic procedures may provide significant therapeutic benefits in severe COVID-19 patients. However, it should be kept in mind that this procedure should only be performed with a rigorous protocol to reduce the risk of aerosol generation and subsequent viral transmission. More well-designed studies are needed to elucidate further the role of bronchoscopic intervention among severely ill COVID-19 patients as well as addressing the most optimal and the safest ventilator setting during the procedure.

\section{References}

1. World Health Organization. Novel Coronavirus-China 2020. WHO Bulletin; 2020. Available from: https://www.who.int/docs/ default-source/coronaviruse/situation-reports/20200211-sitrep22-ncov.pdf?sfvrsn=fb6d49b1 2. [Last Accessed on 2020 Aug 10].

2. Gorbalenya AE, Baker SC, Baric RS, de Groot RJ, Drosten C, Gulyaeva AA, et al. The species severe acute respiratory syndrome-related coronavirus: classifying 2019-nCoV and naming it SARS-CoV-2. Nat Microbiol. 2020;5(4):536-44. https:// doi.org/10.1038/s41564-020-0695-z

3. World Health Organization. Novel Coronavirus (2019-nCoV) Situation Report-1. Geneva: World Health Organization Bulletin; 2020.

4. World Health Organization Bulletin. Coronavirus Disease (COVID-19) Situation Report-108. WHO Bulletin; 2020. Available from: https://www.who.int/docs/default-source/ 
coronaviruse/situation-reports/20200507covid-19-sitrep-108. pdf?sfvrsn=44cc8ed8_2. [Last Accessed on 2020 Aug 15]

5. Huang C, Wang Y, Li X, Ren L, Zhao J, Hu Y, et al. Clinical features of patients infected with 2019 novel coronavirus in Wuhan, China. Lancet. 2020;395(10223):497-506. https://doi. org/10.1016/s0140-6736(20)30183-5

6. Wu C, Chen X, Cai Y, Xia J, Zhou X, Xu S, et al. Risk factors associated with acute respiratory distress syndrome and death in patients with coronavirus disease 2019 pneumonia in Wuhan, China. JAMA Intern Med. 2020;180(7):934-43. https://doi. org/10.1001/jamainternmed.2020.0994

PMid:32167524

7. Nay MA, Mankikian J, AuvetA, Dequin PF, Guillon A. The effect of fibreoptic bronchoscopy in acute respiratory distress syndrome: Experimental evidence from a lung model. Anaesthesia. 2016;71(2):185-91. https://doi.org/10.1111/anae.13274 PMid:26559154

8. Mao $\mathrm{Y}$, Lin $\mathrm{W}$, Wen J, Chen G. Clinical and pathological characteristics of 2019 novel coronavirus disease (COVID-19): A systematic reviews. MedRxiv. 2020;2020:1-31.

9. Guarracino F, Bertini P, Bortolotti U, Stefani M, Ambrosino N. Flexible bronchoscopy during mechanical ventilation in the prone position to treat acute lung injury. Rev Port Pneumol. 2013;19(1):42-4. https://doi.org/10.1016/j.rppneu.2012.06.005 PMid:22868006

10. Kabadayi S, Bellamy MC. Bronchoscopy in critical care. BJA Educ. 2017;17(2):48-56. https://doi.org/10.1093/bjaed/mkw040

11. Pritchett MA, Oberg CL, Belanger A, De Cardenas J, Cheng G. Society for advanced bronchoscopy consensus statement and guidelines for bronchoscopy and airway management amid the COVID-19 pandemic. J Thorac Dis. 2020;12(5):1781-98. https:// doi.org/10.21037/jtd.2020.04.32

PMid:32642084

12. Wahidi MM, Shojaee S, Lamb CR, Ost D, Maldonado F, Eapen G, et al. The use of bronchoscopy during the COVID-19 pandemic: CHEST/AABIP guideline and expert panel report. Chest. 2020;158(3):1268-81. https://doi.org/10.1016/j.chest.2020.04.036 PMid:32361152

13. Lentz RJ, Colt $\mathrm{H}$. Summarizing societal guidelines regarding bronchoscopy during the COVID-19 pandemic. Respirology. 2020;25(6):574-7. https://doi.org/10.1111/resp.13824 PMid:32277733

14. Ashkan MM, Anantham D, Kyle H, Lucia V, Michaela B, Jasleen P, et al. In: Tinku J, editor. International Pulmonologist's Consensus on COVID-19. $2^{\text {nd }}$ ed. India: Amrita Institute of Medical Science; 2020.

15. Fehr AR, Perlman S. Coronaviruses: An overview of their replication and pathogenesis. In: Coronaviruses: Methods and Protocols. United States: Humana; 2015. https://doi. org/10.1007/978-1-4939-2438-7_1

16. Jin $\mathrm{Y}$, Yang $\mathrm{H}$, Ji W, Wu W, Chen S, Zhang W, et al. Virology, epidemiology, pathogenesis, and control of covid-19. Viruses. 2020;12(4):1-17.

PMid:32230900

17. Lauer SA, Grantz KH, Bi Q, Jones FK, Zheng Q, Meredith HR, et al. The incubation period of coronavirus disease 2019 (COVID-19) from publicly reported confirmed cases: Estimation and application. Ann Intern Med. 2020;172(9):577-82. https:// doi.org/10.7326/m20-0504

PMid:32150748

18. World Health Organization. Coronavirus Disease 2019 (COVID-19) Situation Report-73. Geneva, Switzerland: World Health Organization Bulletin; 2020.

19. Wu Z, McGoogan JM. Characteristics of and important lessons from the coronavirus disease 2019 (COVID-19) outbreak in China: Summary of a report of 72314 cases from the Chinese center for disease control and prevention. JAMA. 2020;323(13):1239-42. https://doi.org/10.1001/jama.2020.2648 PMid:32091533

20. Jamil S, Mark N, Carlos G, Cruz CS, Gross JE, Pasnick S. Diagnosis and management of COVID-19 disease. Am J Respir Crit Care Med. 2020;201(10):P19-20. https://doi.org/10.1164/ rccm.2020c1

PMid:32223716

21. Chen $N$, Zhou M, Dong $X, Q u$ J, Gong F, Han $Y$, et al. Epidemiological and clinical characteristics of 99 cases of 2019 novel coronavirus pneumonia in Wuhan, China: A descriptive study. Lancet. 2020;395(10223):507-13. https://doi.org/10.1016/ s0140-6736(20)30211-7

PMid:32007143

22. Yang J, Zheng Y, Gou X, Pu K, Chen Z, Guo Q, et al. Prevalence of comorbidities and its effects in coronavirus disease 2019 patients: A systematic review and meta-analysis. Int J Infect Dis. 2020;94:91-5.

PMid:32173574

23. Cascella M, Rajnik M, Cuomo A, Dulebohn SC, Di Napoli R. Features, Evaluation and Treatment Coronavirus (COVID-19). Treasure Island, FL: StatPearls; 2020.

24. Goh KJ, Choong MC, Cheong EH, Kalimuddin S, Duu Wen S, Phua GC, et al. Rapid progression to acute respiratory distress syndrome: Review of current understanding of critical illness from COVID-19 infection. Ann Acad Med Singapore. 2020;49(1):108-18.

PMid:32200400

25. Fanelli V, Vlachou A, Ghannadian S, Simonetti U, Slutsky AS, Zhang $\mathrm{H}$. Acute respiratory distress syndrome: New definition, current and future therapeutic options. J Thorac Dis. 2013;5(3):326-34.

PMid:23825769

26. Meng L, Qiu H, Wan L, Ai Y, Xue Z, Guo Q, et al. Intubation and ventilation amid the COVID-19 outbreak: Wuhan's experience. Anesthesiology. 2020;132(6):1317-32. https://doi.org/10.1097/ aln.0000000000003296

PMid:32195705

27. Guérin C, Reignier J, Richard JC, Beuret P, Gacouin A, Boulain $\mathrm{T}$, et al. Prone positioning in severe acute respiratory distress syndrome. N Engl J Med. 2013;368(23):2159-68. https://doi.org/10.1056/nejmoa1214103 PMid:23688302

28. Kalchiem-Dekel O, Shanholtz CB, Jeudy J, Sachdeva A, Pickering EM. Feasibility, safety, and utility of bronchoscopy in patients with ARDS while in the prone position. 2018;22:54. https://doi.org/10.1186/s13054-018-1983-3

PMid:29499729 